\title{
The authority of principals' technology leadership in empowering teachers' self-efficacy towards ICT use
}

\author{
Siti Noor Ismail, Mohd Norakmar Omar, Arumugam Raman
}

School of Education, Universiti Utara Malaysia, Malaysia

\section{Article Info \\ Article history: \\ Received Feb 25, 2021 \\ Revised Jun 24, 2021 \\ Accepted Jul 15, 2021}

\section{Keywords:}

Digital leadership

ICT

Principals

Teachers' self-efficacy

Technology leadership

\begin{abstract}
The application of information technology and communication (ICT) in education has a significant impact on teachers. Administrators pressure them to use ICT to improve the quality of teaching and to learn in the classroom. However, teachers are still skeptical of the ability to embody pedagogical strategies through the use of ICT. The purpose of this study was to explore the relationship between principals' technology leadership and teachers' selfefficacy. The study also determined the dimensions of technology leadership that are predictors to the empowerment of teachers' self-efficacy in using ICT. There are two instruments used, namely NETS-A and TSES. The respondents of the study consisted of 376 teachers in Malaysia. The study was conducted based on a quantitative approach, and respondents were selected through multi-level sampling. The results of the t-test found no significant difference for the gender of teachers on the improvement of selfefficacy. Through correlation testing, there was a moderate relationship between technology leadership and teachers' self-efficacy. Even so, there is $24 \%$ of the influence of technology leadership that affects teachers' selfefficacy. Two contributing dimensions are excellence in professional practice and digital citizenship. In summary, principals can generate a revival of teachers' self -efficacy if they wisely encourage them to use ICT. Principals should be role models to teachers and students in ensuring that the concept of pedagogy in the classroom is always carried out through an ICT approach.
\end{abstract}

This is an open access article under the CC BY-SA license.

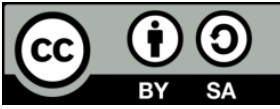

\section{Corresponding Author:}

Siti Noor Ismail

School of Education

Universiti Utara Malaysia

06010 Kedah, Malaysia

Email: siti.noor@uum.edu.my

\section{INTRODUCTION}

The formal learning system starts from the transmission of knowledge in schools. Students are nurtured and educated with various skills through trained teachers. Teachers have a great responsibility to ensure that all students can master what is taught. They are also the driving force in the formation of a student's personality. Therefore, teachers need to have commitment, motivation and self-ability to form brilliant students' learning and personality [1]. This includes improving the quality of teachers' teaching so that the objectives to be conveyed can be channeled more perfectly [2]. In previous study, it proved that the effectiveness of teacher pedagogy lies in their ability to produce excellent students in any field [3]. Meaning, the ability of teachers to process good pedagogy is the meeting point to teaching effectiveness and student excellence.

Their level of self-efficacy often influences well-established teachers' pedagogical methods. It is undeniable that perfect pedagogical practice affects the improvement of self-efficacy. It also has a 
significance on the learning atmosphere in the organization [4]. Turning to the model of self-efficacy, there are three elements to build educators' self-efficacy, namely teaching strategies, classroom management and student engagement. This model suggests that the teacher mastered these elements in becoming a competent educator towards the triggers of student excellence. Nevertheless, the fact is that a teacher's challenge to build the desired pedagogical strategy still has constraints, especially in tackling problems related to the level of readiness of students [5].

Nowadays, teachers face various dilemmas in educating students. Despite having a complete instructional plan, teachers should ensure that their pedagogical strategies cross the curriculum and meet 21st-century learning standards [6]. The advent of information technology and communication (ICT) has brought a new dimension to student learning patterns. Like it or not, teachers need to follow ICT development, such as mastering mobile technology devices that are gaining ground in today's education [7]. In such circumstances, the ability of teachers to organize pedagogy based on the use of the latest technology is an indicator of increased self-efficacy. However, a question arises, to what extent is the ability of teachers to embody pedagogical excellence through ICT? Does the issue also arise how teachers can administer the classroom and attract students to participate in each activity through the ICT approach? The keyword is that teachers cannot ignore the concept of learning through technology as it has become a new norm in today's education system [8].

In PISA's planning for 2021, self-efficacy on ICT is a contingency character that teachers should master, in addition to the ability to adapt to the latest digital devices [9]. This case is because a high level of self-efficacy will lead to the effectiveness of planned pedagogy, even using ICT. Several studies agree that the use of technology in teaching formation is due to teachers' high self-efficacy and teachers' competence in ICT [10], [11]. However, teachers need the support of all school communities to rekindle their enthusiasm to continue to demonstrate the quality of teaching. Authoritative individuals such as principals should play a role in encouraging teachers' ICT use in shaping more meaningful learning. This phenomenon is because principals are the most influential individuals, and the rise of a school organization depends heavily on their hands [12].

The concept of excellent principal administration is through their involvement in every planned activity [13]. The principal is also the best role model and follower of every citizen in the organization he or she leads. Principals can also be the trigger for the more safe, legal and ethical use of ICT. Therefore, the question that arises is what the best character for principals to implement to raise the ability of teachers to use ICT in schools is? Previously, studies by Esplin, Stewart, Thurston [14] and Yu and Prince [15] suggested principals should understand and deepen the character as a technology leader recommended by the National Educational Technology Standards for Administration (NETS-A). Proven through their research, a technology leader can trigger a teacher's ability in using ICT in the classroom. Besides, the character of a technology leader is so synonymous with the excellence of administering and managing ICT-based school organizations.

Efforts towards organizational management excellence will be fruitful if principals successfully master the knowledge and skills related to ICT. Accordingly, there is a suggestion that all principals strengthen ICT competencies as a ticket to deepen the character of technology leadership [16]. ICT competencies can build through professional development programs that emphasize organizational management and administration aspects through a technological approach [17]. Only through ICT knowledge and skills can help principals trace the true character of technology leadership. Are principals able to adopt the character of technology leadership to enhance the ability of teachers to use ICT in schools? Is teacher self-efficacy a trigger for the use of ICT in pedagogical methods?

These issues are the central polemics and debates in the construction of the research questions as: 1) What is the level of technology leadership and teachers' self-efficacy in Malaysia? 2) Does teachers' self efficacy differ in terms of gender? 3) Is there a relationship between technology leadership and teachers' selfefficacy? 4) Whether the dimensions of technology leadership contribute to the teachers' self-efficacy?

\section{RESEARCH METHOD}

\subsection{Research design and sampling}

The study's main objective was to identify the dimensions of technological leadership that influence teachers' self-efficacy. Thus, the quantitative approach using a questionnaire is a strategy taken to obtain research information. According to Creswell [18], a quantitative approach can study the attitudes and behaviors of respondents who have characteristics that are very similar to the actual population. Through questionnaires, information is collected more quickly and is suitable to be applied to prominent study locations. In this study, the study population is teachers who serve in secondary schools around Kedah, Malaysia. 
The sample selection method uses multi-stage sampling to consider some constraints and recommendations by Sekaran and Bougie [19]. Initially, schools distributed according to study zones. At this stage, the selection of three school zones was determined based on random cluster sampling. Then, the schools distributed according to the location of placement. This method is based on stratified random sampling to determine 24 selected schools according to urban or rural areas. In the next step, the sample was selected based on systematic random sampling to obtain 376 teachers from the 24 schools. The study also found written approval from the Ministry of Education Malaysia (MOE) and the Kedah State Education Department (JPN Kedah).

\subsection{Instrumentation}

Measurement of technology leadership using the NETS-A instrument issued by ISTE [20]. The organization [20] is an independent community body that seeks to raise the quality of educators through the use of ICT. Also, the measurement of technology leadership adapted from the instrument [16]. This NETS-A instrument has 32 items covering five dimensions of technology leader character. All NETS-A items and dimensions have high-reliability values. Previously, Wei [16] found the reliability values of NETS-A items in his study to be around 0.91 to 0.94 . Besides, a study found that NETS-A items recorded a reliability value of 0.93 overall [21]. In this study, Cronbach's alpha values for all dimensions were between 0.88 and 0.94 . This case proves that NETS-A is very suitable to be used for conducting further studies.

Meanwhile, the Teacher Sense of Efficacy Scale (TSES) is an instrument used to measure teachers' self-efficacy. The TSES instrument was adapted from Tschannen-Moran and Hoy [22] and absorbed with ICT elements in teacher teaching. A study by Zee, Koomen, and de Jong [23] found that the reliability value of the TSES item in his study was 0.87. Meanwhile, Sakiz, Ekinci, and Saricam [24] found that TSES in his study translated into Turkish had a Cronbach's alpha value ranging from 0.83 to 0.93 . In this study, the reliability value for TSES was around 0.95 overall, covering 24 items.

\subsection{Normality and data analysis}

Before the implementation of the study, the data collected through a normalization phase. Normality testing is the earliest phase to ensure that each study data typically distributed. Normality tests also prove that the data obtained have a high degree of consistency [18]. Typically, the data normality range is around +1.96 to -1.96 , taking into account the values for skewness and kurtosis [25]. In this study, all items and dimensions of technology leadership normally distributed where the overall value of skewness was 0.12 and kurtosis were 0.28 . Data normality also exhibited for teachers' self-efficacy items where the overall skewness value was 0.02 and kurtosis was 0.55 .

Next, SPSS software was used to analyze the raw data. There are four analytical breakdowns in this study. Initially, the levels of variables were measured using descriptive statistical methods. Then, gender differences based on self-efficacy tested via t-test. Subsequently, the relationship between the two study variables explored through Pearson's correlation test. Finally, the determination of predictor dimensions in technology leadership was generated based on multiple regression analysis. All study significance levels refer to $p$ values below 0.05 as suggested by Creswell [18] and Hair, et al. [25].

\section{RESULTS}

\subsection{Question 1: The level of technology leadership and teachers' self-efficacy}

Levels of technology leadership and teachers' self-efficacy were analyzed using descriptive statistical methods. The mean value (M) and the standard deviation value (SD) obtained to determine a certain variable level through this method. The test found that the level of technology leadership was high overall $(\mathrm{M}=3.81, \mathrm{SD}=0.48)$. Besides, the level of teachers' self-efficacy recorded a high value $(\mathrm{M}=3.84$, $\mathrm{SD}=0.42$ ). The interpretation of the mean value refers to Hussin, Ali, and Noor [26], where the high level is between 3.41 to 4.20. The overall summary of the descriptive statistical tests is shown in Table 1 .

Table 1. The level of variable

\begin{tabular}{cccc}
\hline Variable & Mean & SD & Result \\
\hline Technology leadership (Overall) & 3.81 & 0.48 & High level \\
Visionary leadership (VL) & 3.95 & 0.53 & High level \\
Digital age learning culture (LC) & 3.86 & 0.58 & High level \\
Excellence in professional practice (PP) & 3.81 & 0.54 & High level \\
Systemic improvement (SI) & 3.70 & 0.60 & High level \\
Digital citizenship (DC) & 3.72 & 0.55 & High level \\
Teachers' self-efficacy (Overall) & 3.84 & 0.43 & High level \\
\hline
\end{tabular}


Meanwhile, the five dimensions of technology leadership also recorded high values, preceded by the dimension of visionary leadership $(\mathrm{M}=3.95, \mathrm{SD}=0.53)$, and ended by the dimension of systemic improvement $(\mathrm{M}=3.70, \mathrm{SD}=0.60)$. This case gives the impression that a clear vision and objectives in the organization will guide principals to move schools towards more structured ICT integration. Principals can also implement planned activities according to need as agreed through the school's ICT strategic planning plan.

Although the systemic improvement dimension is the lowest among these five dimensions, it does not mean that principals ignore the proposed character. Even a high level shows that principals can make ICT improvements in schools well and continuously according to current needs. Overall, it found that the principals in Kedah are ready to adopt the concept of technology leadership. Teachers' confidence found to be increasing despite the challenges of educating students through ICT approaches.

\subsection{Question 2: The differences of teachers' self-efficacy (based on teachers' gender)}

The t-test used to test gender differences in teachers' self-efficacy. The Levene's test results found that both gender groups, whether male or female, were independent of each other $(\mathrm{p}=0.10, \mathrm{p}>0.05)$. This condition indicates that the homogeneity of variance between the sexes observed. Based on the t-test, it was found that the mean for male teachers $(\mathrm{M}=3.90, \mathrm{SD}=0.49)$ was higher than that of female teachers $(\mathrm{M}=3.82$, $\mathrm{SD}=0.39$ ). The mean difference for these two gender groups was shallow. Thus, the findings show no significant difference in teacher gender on self-efficacy, where the value of $t(374)=1.67, p=0.10$. In simple words, the self-efficacy for male and female teachers was almost the same, and the ICT approach applied did not make any difference between the two groups. Table 2 shows the t-test analysis performed.

Table 2. T-test analysis (based on teachers' gender)

\begin{tabular}{lccccc}
\hline Gender & $\mathrm{N}$ & Mean & SD & t-value & df \\
\hline Male & 104 & 3.90 & 0.49 & 1.67 & 374 \\
Female & 272 & 3.82 & 0.39 & & \\
\hline
\end{tabular}

\subsection{Question 3: The relationship between technology leadership and teachers' self-efficacy}

Pearson's correlation test is a method used to determine the relationship between the two study variables. Based on the test, it found that there was a moderate relationship between technology leadership and teachers' self-efficacy ( $\mathrm{r}=0.48)$. The strength of the correlation value is referred to Hussin, Ali, and Noor [26], where the moderate relationship is between 0.40 to 0.59 . These findings bring to light where the ability of teachers to use ICT in the classroom is the result of support from a technology leader. The encouragement and words of encouragement of administrators are crucial to increasing teachers' self-efficacy to produce technology-based pedagogy. Table 3 shows the relationship between the two variables.

Table 3. The correlation between two variables

\begin{tabular}{ccccccc}
\hline & Variable & $\mathrm{N}$ & Mean & SD & 1 & 2 \\
\hline 1. & Technology leadership & 376 & 3.81 & 0.48 & 1 & $0.48^{* *}$ \\
2. & Teachers' self-efficacy & 376 & 3.84 & 0.43 & & 1 \\
\hline
\end{tabular}

\subsection{Question 4: The contribution of technology leadership on teachers' self-efficacy}

In answering this question, multiple linear regression used to identify the dimensions of technology leadership that influence teachers' self-efficacy. First, the ANOVA test showed that is significant, where $\mathrm{F}(5,370)=21.38, \mathrm{p}=0.00$. Next, the summary model in multiple linear regression found that the value of $r$ square $\left(r^{2}\right)$ is 0.24 . This case means a $24 \%$ variance in the technology leadership variable contributing to the increase in teachers' self-efficacy. Although the value of this variance is low, it already illustrates the role of technology leaders in raising the ability of teachers to use ICT to diversify teaching strategies. Table 4 shows a summary model of the results of multiple regression analysis.

Table 5 shows the significant values for all principals' technology leadership dimensions on selfefficacy. The test results found that two dimensions affect the self-efficacy of teachers in using ICT, namely excellence in professional practice $(\beta=0.22)$ and digital citizenship $(\beta=0.18)$. These findings indicate that the professional practices by principals can strengthen the teachers' self-efficacy further. Simultaneously, the principals' exemplary practices can follow by every teacher in ensuring that ICT used more legally, safely and ethically. 
Table 4. Model summary (multiple linear regression)

\begin{tabular}{ccccc}
\hline Model & $\mathrm{R}$ & $\mathrm{R}^{2}$ & Adjusted R $^{2}$ & Std. Error (SE) \\
\hline 1 & 0.48 & 0.24 & 0.22 & 0.38 \\
\hline
\end{tabular}

Table 5. The result of multiple linear regression

\begin{tabular}{|c|c|c|c|c|c|}
\hline \multirow{2}{*}{ Dimensions } & \multicolumn{2}{|c|}{ Unstandardized coefficients } & \multicolumn{3}{|l|}{ Standardized coefficients } \\
\hline & $\mathrm{B}$ & $\mathrm{SE}$ & $\operatorname{Beta}(\beta)$ & $\mathrm{t}$ & Sig. \\
\hline (Constant) & 2.37 & 0.15 & & 15.11 & 0.00 \\
\hline Visionary leadership & 0.02 & 0.05 & 0.03 & 0.44 & 0.66 \\
\hline Digital age learning culture & 0.04 & 0.06 & 0.06 & 0.67 & 0.50 \\
\hline Excellence in professional practice & 0.16 & 0.07 & 0.22 & 2.41 & 0.02 \\
\hline Systemic improvement & 0.04 & 0.06 & 0.06 & 0.74 & 0.46 \\
\hline Digital citizenship & 0.12 & 0.06 & 0.18 & 1.98 & 0.04 \\
\hline
\end{tabular}

\section{DISCUSSION}

Nowadays, ICT has brought many advantages to the educational transformation of the country. The application of ICT is not only on the management aspect of school administration but also on the formation of daily pedagogy. Frequent use of ICT will give high confidence to teachers to implement various other innovations in their teaching. Studies by Atabek [8] and Lailiyah and Cahyono [27] found that the challenge of teachers using ICT in the classroom is not a barrier to improving their self-efficacy. Although teachers have to process teaching according to the appropriate level of student acceptance, they can focus entirely on learning objectives. The thing that can commend is the initiative of teachers by taking into account the background of students and their concerns, making the learning process easy to implement [4]. Despite using ICT, teachers understand what students' needs should meet before solving other more extensive problems.

The challenge for teachers in using ICT is to ensure that students are involved in every activity planned. Previous study showed that teachers who wisely plan and diversify teaching activities could boost student engagement [28]. Therefore, the attitude of teachers needs to be changed and create a positive mentality to see students achieve success. According to Poulou, Reddy, and Dudek [2], teachers' expertise in managing the classroom is among the causes of their teaching process being more effective while creating a stimulating environment. It is undeniable that using ICT in teaching comes from the high level of selfefficacy of teachers [29]. Therefore, teachers advised being more courageous and confident in their abilities as it can bring about internal motivation, thus increasing their self-efficacy.

The study also showed a high level of technology leadership among principals in the state of Kedah. The phenomenon sparked a new revolution in the leadership style of a school leader, where the principal is capable of functioning as a technology leader. Previous studies show that character in NETS-A is well suited to be practiced by principals in order to empower themselves as technology leaders [16], [21], [30]. When principals can deepen and master NETS-A, it is inevitable that they have placed a high technology leadership character [7]. In NETS-A, a principal who adopts a technology leadership style should establish a clear ICT vision in the organization while ensuring a technology-driven learning culture in schools. They should also enhance ICT competencies through ICT professional development programs to transform the organization to the most optimal level of technology integration.

Meanwhile, the study found that male teachers and female teachers had no difference in selfefficacy despite using ICT in teaching. Studies by Wei [16] and George, Richardson, and Watt [31] state that this situation occurs when teachers have already shown confidence and can place themselves at their maximum performance. It also contributed by good work performance, high commitment and positive behaviors in performing each responsibility. Besides, teachers' seriousness and job satisfaction in imparting knowledge is one reason for the production of excellent students in various fields, either academically or cocurricular [23].

Nowadays, the gender factor is no longer used to determine the pedagogical excellence of a teacher in a school. The most important thing is how teachers process teaching objectives to become more interesting through a technological approach [10]. A teacher's dream is none other than to educate students to become human beings who master various fields, either theoretically or even skilled in practice. In this case, the term gender discrimination cannot exist because the primary goal of education is to realize every planned objective. A study found that teachers will work hard to design appropriate pedagogical strategies according to the ICT competencies [11]. In reality, administrators cannot set high targets because teachers' level of ICT competence varies according to their knowledge and skills [32], [33].

As principals, one of their responsibilities is to ensure that every objective in the organization has a clear goal. Principals are the best individuals producing job satisfaction, self-efficacy and well-being of teachers in organizations [1]. The study also found that principals who practiced technology leadership could 
produce a relationship with teachers' self -efficacy even in moderate relationships. The findings of this study are in line with Tiop, Talip [34] and Weng, Tang [35], where their study found that high teacher self-efficacy was present from the integration of principals leading schools based on NETS-A practices in technology leadership. Competent principals will ensure that teachers are always confident in organizing the teaching process even with the help of the latest technology. Therefore, technology leaders should focus on providing the best services to teachers, including providing adequate ICT infrastructure and technical support so that the technology used can drive the implementation of the school curriculum.

The education system in schools is now moving towards the Industrial Revolution 4.0. Indirectly, implementing the pedagogy currently practiced should align with the latest learning requirements geared towards 21st-century learning [6]. In this phenomenon, principals have a high responsibility to ensure that teachers can implement pedagogical changes towards using ICT if principals fully understand the character of technology leadership. Among those suggested by Gilkes [11] and Wei [16] is that principals should strive to encourage teachers to improve self-efficacy and competence in ICT to generate more exciting learning activities in the classroom. Therefore, teachers are encouraged to participate in ICT professional development programs so that their ICT knowledge and skills are augmented and adapted to the concept of learning in secondary schools [17]. These programs can strengthen teachers' self-efficacy, thus triggering their ability to use the latest technology and software in organizing pedagogy. If this is the case, then the principal is said to function as a natural technology leader.

The findings also indicate that the dimensions of technology leadership have significant and predictive to teachers' self-efficacy. These findings are in line with Thannimalai, Raman [21] and Weng, Tang [35], who found that the effectiveness of teachers' teaching using ICT lies in the actual character of the principal as a technology leader. The studies did not focus on teachers' self-efficacy, but their contribution was to the character of principals who successfully practiced the elements of NETS-A. The unceasing support from the principals gave rise to the extraordinary ability of the teachers to use ICT in the classroom. The influence of the principal should be used as much as possible, mainly to ensure that teachers constantly improve the quality of teaching through the use of more digital technology [36].

The two dimensions of NETS-A which are predictors of the self-efficacy of secondary school teachers in the state of Kedah are excellence in professional practice and digital citizenship. Previously, Yu and Prince [15] agreed that these dimensions could trigger principals' interest to further delve into the latest technological developments to apply in schools' currents. Besides, these dimensions are also used as indicators of ICT culture in a school organization. According to Esplin, Stewart, and Thurston [14], excellent professional practice is the best step in channeling all school people from top management, teachers, and students. Meanwhile, the practice of digital citizenship among principals prioritizes the safe, legal and ethical use of ICT in every activity, especially the use of resources in cyberspace [30], [37]. Thus, the characters of technology leadership are the trigger to the higher confidence of teachers to be able to use more sophisticated digital devices.

\section{CONCLUSION}

Overall, this study produced a positive contribution in further developing the talents of principals as technology leaders. It is even more gratifying when the dimensions of excellence in professional practice and digital citizenship lead the NETS-A characters to guide principals to encourage teachers to empower selfefficacy. This situation will indirectly help teachers use their existing competencies to diversify technologybased pedagogical methods. Highly effective teachers will also work hard to gain knowledge and improve ICT skills to weather the changes in the country's increasingly challenging education system. This situation is the beginning of the current of education directed towards the formation of 21 st-century learning. The use of ICT can help teachers achieve teaching objectives and increase the interest, involvement, and excitement of students in every activity in the classroom.

However, there are still improvements that need to be implemented by principals to ensure that they fully master the character of technology leaders. The situation based on three more dimensions, namely visionary leadership, digital age learning culture and systemic improvement, which must be improved from time to time. Logically, if principals' practice is reinforced, it is likely that these three elements can also have a significant impact on teachers' self-efficacy. It also influenced by other factors such as school climate, study location, environmental culture and different study approaches. Future studies will be more interesting if they can highlight the empirical evidence on the development of teacher self-efficacy. Besides, it suggested that future studies apply model testing using structural equation modeling (SEM). With the SEM method, a model can be extracted visually and verifies the reliability of the model more transparently. 


\section{REFERENCES}

[1] S. Huang, H. Yin, and L. Lv, "Job characteristics and teacher well-being: The mediation of teacher self-monitoring and teacher self-efficacy," Educational Psychology, vol. 39, no. 3, pp. 313-331, 2019.

[2] M. S. Poulou, L. A. Reddy, and C. M. Dudek, "Relation of teacher self-efficacy and classroom practices: A preliminary investigation," School Psychology International, vol. 40, no. 1, pp. 25-48, 2019.

[3] S. M. Warrah, K. W. Bing, and H. Yusof, "Developing and validating model of teacher quality using structural equation modeling (SEM) technique," Malaysian Online Journal of Educational Management, vo. 6, no. 3, pp. 1-28, 2018.

[4] E. Choi, and J. Lee, "EFL teachers' self-efficacy and teaching practices," ELT Journal, vol. 72, no. 2, pp. 175-186, 2018.

[5] L. Shengnan and P. Hallinger, "Unpacking the effects of culture on school leadership and teacher learning in China," Educational Management Administration \& Leadership, vol. 49, no. 2, pp. 214-233, 2021.

[6] S. Drake, and J. Reid, "Integrated curriculum as an effective way to teach 21 st century capabilities," Asia Pacific Journal of Educational Research, vol. 1, no. 1, pp. 31-50, 2018.

[7] M. N. Omar, and S. N. Ismail, "Mobile technology integration in the 2020s: The impact of technology leadership in the Malaysian context," Universal Journal of Educational Research, vol. 8, no. 5, pp. 1874-1884, 2020.

[8] O. Atabek, "Associations between emotional states, self-efficacy for and attitude towards using educational technology," International Journal of Progressive Education, vol. 16, no. 2, pp. 175-194, 2020.

[9] A. Lorenceau, C. Marec, and T. Mostafa, "Upgrading the ICT questionnaire items in PISA 2021," OECD Education Working Papers, No. 202, OECD Publishing, Paris, 2019.

[10] J. Crossan, "Thai teachers' self-efficacy towards educational technology integration," Assumption UniversityEJournal of Interdisciplinary Research, vol. 5 no. 1, pp. 107-123, 2020.

[11] A. L. Gilkes, "Teachers' knowledge and self-efficacy beliefs as factors affecting technology integration practices," Doctoral Thesis, Walden University, 2020.

[12] A. Taufik, and Z. Istiarsono, "Perspectives on the challenges of leadership in schools to improve student learning systems," International Journal of Evaluation and Research in Education (IJERE), vol. 9 no. 3, pp. 600-606, 2020.

[13] Y. Liu, M. S. Bellibas, and S. Gumus, "The effect of instructional leadership and distributed leadership on teacher self-efficacy and job satisfaction: Mediating roles of supportive school culture and teacher collaboration," Educational Management Administration \& Leadership, vol. 49, no. 3, pp. 430-453, 2021.

[14] N. L. Esplin, C. Stewart, and T. N. Thurston, "Technology leadership perceptions of Utah elementary school principals," Journal of Research on Technology in Education, vol. 50, no. 4, pp. 1-14, 2018.

[15] C. Yu, and D. L. Prince, "Aspiring school administrators' perceived ability to meet technology standards and technological needs for professional development," Journal of Research on Technology in Education, vol. 48, no. 4, pp. 239-257, 2016.

[16] L. M. Wei, "Principal technology leadership practices, teacher ICT competency, and teacher acceptance of School Management System (SMS) in Negeri Sembilan secondary schools," Doctoral Thesis, University of Malaya, 2017.

[17] A. Raman and R. Thannimalai, "Importance of technology leadership for technology integration: Gender and professional development perspective," SAGE Open, vol. 9, no. 4, pp. 1-13, 2019.

[18] J. W. Creswell, Research design: Qualitative, quantitative, and mixed methods approaches, 4th ed. Thousand Oaks, California: SAGE Publications, Inc, 2014.

[19] U. Sekaran and R. Bougie, Research methods for business: A skill building approach, 7th ed. Chichester, West Sussex: John Wiley \& Sons Ltd, 2016.

[20] International Society for Technology in Education (ISTE), "ISTE Standards for Administrators," 2009. [Online]. Available: https://www.iste.org.

[21] R. Thannimalai, and A. Raman, "The Influence of principals' technology leadership and professional development on teachers' technology integration in secondary schools," Malaysian Journal of Learning and Instruction, vol. 15, no. 1, pp. 203-228, 2018.

[22] M. Tschannen-Moran, and A. W. Hoy, "Teacher efficacy: Capturing an elusive construct," Teaching and Teacher Education, vol. 17, pp. 783-805, 2001.

[23] M. Zee, H. M. Y. Koomen, and P. F. de Jong, "How different levels of conceptualization and measurement affect the relationship between teacher self-efficacy and students' academic achievement," Contemporary Educational Psychology, vol. 55, pp. 189-200, 2018.

[24] H. Sakiz, A. Ekinci, and H. Saricam, "Teachers' perceptions of their school managers' skills and their own selfefficacy levels," International Journal of Leadership in Education, vol. 23, no. 5, pp. 585-603, 2020.

[25] J. J. F. Hair, W. C. Black, B. J. Babin, and R. E. Anderson, Multivariate data analysis, 7th ed. Essex: Pearson Education Limited, 2014.

[26] F. Hussin, J. Ali, and M. S. Z. Noor, Kaedah penyelidikan \& analisis data SPSS. Sintok, Kedah: UUM Press, 2014.

[27] M. Lailiyah and B. Y. Cahyono, "Indonesian EFL teachers' self-efficacy towards technology integration (SETI) and their use of technology in EFL teaching," Studies in English Language Teaching, vol. 5, no. 2, pp. 344-357, 2017.

[28] T. Schipper, S. L. Goei, S. de Vries, and K. van Veen, "Developing teachers' self-efficacy and adaptive teaching behaviour through lesson study," International Journal of Educational Research, vol. 88, pp. 109-120, 2018.

[29] A. B. Hall, and J. Trespalacios, "Personalized professional learning and teacher self-efficacy for integrating technology in K-12 classrooms," Journal of Digital Learning in Teacher Education, vol. 35, no. 4, pp. 221-235, 2019. 
[30] N. G. Ugur and T. Koc, "Leading and teaching with technology: School principals' perspective," International Journal of Educational Leadership and Management, vol. 7, no. 1, pp. 42-71, 2019.

[31] S. V. George, P. W. Richardson, and H. M. G. Watt, "Early career teachers' self-efficacy: A longitudinal study from Australia," Australian Journal of Education, vol. 62, no. 2, pp. 217-233, 2018.

[32] R. Cansoy, and H. Parlar, "Examining the relationship between school principals' instructional leadership behaviors, teacher self-efficacy, and collective teacher efficacy," International Journal of Educational Management, vol. 32, no. 4, pp. 550-567, 2018.

[33] M. N. Omar, S. N. Ismail, and A. L. Kasim, "Hubungan kepimpinan teknologi pengetua dan efikasi kendiri guru," Jurnal Kepimpinan Pendidikan, vol. 6, no. 4, pp. 1-21, 2019.

[34] T. Tiop, and R. Talip, "Hubungan kepimpinan teknologi pengetua dalam pengurusan kurikulum dan efikasi kendiri guru," Malaysian Journal of Social Sciences and Humanities (MJSSH), vol. 5, no. 4, pp. 71-83, 2020.

[35] C. H. Weng, and Y. Tang, "The relationship between technology leadership strategies and effectiveness of school administration: An empirical study," Computers \& Education, vol. 76, pp. 91-107, 2014.

[36] J. L. Hero, "Exploring the principal's technology leadership: its influence on teachers' technological proficiency," International Journal of Academic Pedagogical Research, vol. 4, no. 6, pp. 4-10, 2020.

[37] M. T. Machmud, A. P. Widiyan, and N. R. Ramadhani, "The development and policies of ICT supporting educational technology in Singapore, Thailand, Indonesia, and Myanmar," International Journal of Evaluation and Research in Education (IJERE), vol. 10, no.1, pp. 78-85, 2021. 